\title{
Affordability Issues Of Biotech Drugs In Low- And Middle-Income Countries (Lmics)- Short Communication
} \author{
Bangladesh

\section{${ }^{*}$ Corresponding Author} \\ Abdul Kader Mohiuddin

\section{Article History} \\ Received: 27.07.2019 \\ Accepted: 16.08 .2019 \\ Published: 30.09 .2019
}

Abdul Kader Mohiuddin*

Assistant Professor, Department of Pharmacy, World University of Bangladesh, 151/8, Green Road, Dhanmondi, Dhaka - 1205,

\begin{abstract}
As indicated by World Bank publication Disease Control Priorities: Improving Health and Reducing Poverty (third edition, 2017), about $20 \%$ all out health use universally originated from out-of-pocket payments in 2014 . The equivalent was about $40 \%$ all out health use for low-income countries, $56 \%$ for lower-middle-income countries, and 30\% for upper-middle-income countries (WHO, 2016). 33\% of the world's populace needs opportune access to quality-guaranteed medicines while assessments demonstrate that in any event $10 \%$ of medicine in low-and middle-income countries (LMICs) are substandard or distorted, costing roughly US\$ 31 billion every year (Global Health, 2018). Shockingly, $80 \%$ of worldwide cardiovascular passings happen in LMICs which is (halfway) because of the absence of access to healthcare including talented HR, equipped offices and medicines (Global status report on noncommunicable diseases, WHO, 2010). Cost of drugs, antibodies, and diagnostics is a noteworthy weight in LMICs round the globe. Cost of biotech drugs are much higher because of surprising expense caused by the pharmaceutical organizations for clinical preliminary. Biotech drugs have totally changed the administration of a few diseases, including malignant growth and immune system diseases. Albeit essential yet their affordability is as yet a consuming issue, particularly in LMICs.
\end{abstract}

Keywords: LMICs; out-of-pocket expenditure; cancer treatments; biotech drugs; pharmaceutical patents; biosimilars

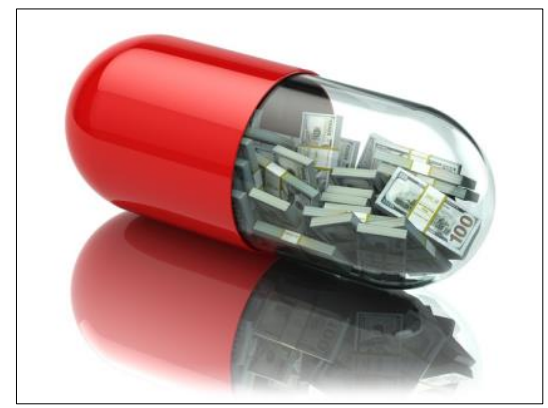

Fig-1: High cost involved in biotech drugs.

Biotech organizations for the most part have high working expenses as they are engaged with research, advancement, and testing that takes a long time to finish. The outcome could be a noteworthy achievement or articulate disappointment. Additionally, regardless of whether an organization carries another prescription to the market, it doesn't mean it will increase broad doctor endorsement and use (Source: Segal T. Biotech vs. Pharmaceuticals: What's the Difference? Investopedia, Jun 25, 2019).

Pharmaceutical organizations put resources into the improvement and testing of their drugs including by financing clinical preliminaries. Moreover, pharmaceutical organizations additionally spend a lot of cash on publicizing. For example, in 2016 US\$6.7 billion was spent on direct-to-buyer pharmaceutical publicizing alone in the USA [1]. Worldwide spending on medicines came to $\$ 1.2$ trillion of every 2018 and will surpass $\$ 1.5$ trillion by 2023, as per "The Global Use of Medicine in 2019 and Outlook to 2023" [2,3]. In spite of the fact that, entrance to essential medicines is hazardous for $33 \%$ of all people worldwide [4]. Restricted access to essential

Copyright @ 2019: This is an open-access article distributed under the terms of the Creative Commons Attribution license which permits unrestricted use, distribution, and reproduction in any medium for non commercial use (NonCommercial, or CC-BY-NC) provided the original author and source are credited. 
medicines (EMs) for treating chronic diseases is a noteworthy test in low-and middle-income countries (LMICs) $[4,5]$. Normal public part accessibility of even low-cost conventional medicines ranges from $30 \%$ to $55 \%$ crosswise over 36 LMICs [6]. Cost of drugs, antibodies, and diagnostics is a noteworthy weight in 105 middle income countries round the globe, containing $70 \%$ of the world populace, $75 \%$ of the poor [7]. While public hospitals offer free or subsidized treatment including essential medicines, the high patient caseloads, underfunding and wasteful medicine dispersion frameworks are boundaries to predictable administration arrangement [8]. Additionally, $90 \%$ of the populace in creating countries buy medicines all through of-pocket (OOP) payments [7]. Poor accessibility of medicines in the public part has pushed up household OOP use, making them the biggest household consumption thing after nourishment [9]. Non-communicable diseases (NCDs) which, as per WHO are currently the world's greatest executioners. More than 36 million individuals kick the bucket every year (63\% of global passings) from NCDs, essentially CVDs, cancer, chronic respiratory diseases and diabetes. Of these, $80 \%$ happen in LMICs [10]. Along these lines, The WHO has set at least $80 \%$ as objective accessibility of medicines for both communicable and non-communicable diseases in all countries [11]. Yet, Pharmaceutical organizations have a substantial want in creating drugs for chronic diseases and cancer treatments, because of high commonness, yet additionally because these drugs are regularly used in long haul [12]. Pharmaceutical licenses keep up medication costs well over the cost of creation and can limit access to required medicines [13]. Biotech drugs have totally changed the administration of a few diseases, including cancer and immune system diseases, for example, psoriasis, rheumatoid joint pain, multiple sclerosis, and inflammatory bowel disease [14]. The mind-boggling expense of biotech prescriptions (focus on a quality or protein and regularly are infused or infused, related with treating a chronic condition) frequently requires noteworthy OOP uses [15,16]. A few examinations state that pharmaceutical organizations value drugs monopolistically, secured by patent rights, while others accept that the high costs for vagrant drugs basically allow sedate R\&D and creation costs. In any case, the global vagrant medication market is evaluated to contact US $\$ 209$ billion by 2022 representing $21.4 \%$ of complete branded physician endorsed sedate deals [17]. As per the Tufts Center for Drug Development, it costs, by and large, $\$ 100$ million out of 1975 , around $\$ 900$ million preceding 2004 and 1.3 billion after 2005 to build up another medication and put up it for sale to the public $[18,19]$. While, Scavone et.al, 2019 detailed that whole time that goes from the R\&D stage until the medication's advertising endorsement can last as long as 15 years, and it is portrayed by amazingly mind-boggling expenses, normally surpassing $\$ 1.2$ billion [20]. Gouglas et.al, 2018 assessed at least $\$ 2 \cdot 8-3 \cdot 7$ billion $(\$ 1 \cdot 2$ billion-\$8.4 billion territory) for one immunization all the way to the finish of stage 2a among 11 pandemic infectious diseases [21]. Aside from the customary plan of RCT, lately further examination structures, including umbrella, container and stage preliminaries, were created and connected to new treatments, particularly in the zone of oncology look into [22]. Tay-Teo et.al, 2019 expressed the most normally acknowledged assessments of R\&D costs, including cancer drugs, are between $\$ 200$ million and $\$ 2.9$ billion, after modifications for the likelihood of disappointment and opportunity costs [23]. Genomic studies directed in the previous two decades recognized the sub-atomic drivers of specific cancers and prompted the approach of focused treatments as a significant extra mainstay of the cancer treatment armamentarium [24]. As per the Global Oncology Trend Report, global spending on cancer drugs ascended from $\$ 75$ billion of every 2010 to $\$ 100$ billion out of $2014,10.3 \%$ ascent in spending. Asia represents $60 \%$ of the world populace and half of the global weight of cancer [25]. There are more than 100 sorts of cancers, situated in various organs and subtissues and beginning from various cell types. Some cancer types (e.g., colon, bosom, and non-Hodgkin's lymphoma) contain significantly increasingly explicit groupings dependent on their sub-atomic subtypes. In spite of this multifaceted nature and inconstancy, most sorts of cancer are treated with similar non-exclusive treatments [26]. Faultfinders guarantee that costs of creative drugs are over the top and contend that lowering costs won't hurt the flourishing advancement. On the furthest edge, the pharmaceutical business demands that prohibitive valuing arrangements will detrimentally affect their capacity to produce advancement [27]. During 2017, PIVI worked with its nation accomplices and the WHO territorial and nearby workplaces to survey NITAGs fortifying needs and to give specialized help with 7 LMICs (Laos Peoples Democratic Republic, Mongolia, Vietnam, Armenia, Côte d'Ivoire; Moldova and the Republic of Georgia) [28]. In Europe, complete cancer tranquilize deals dramatically increased somewhere in the range of 2005 and 2014, expanding from $€ 8.0$ billion to $€ 19.8$ billion [29]. Biologics were assessed to represent US $\$ 289$ billion pharmaceutical deals in 2014 and are anticipated to reach US $\$ 445$ billion of every 2019 . It is additionally foreseen that a lot of global solution and OTC pharmaceutical deals will ascend to $26 \%$ by 2019 [30]. It is anticipated that new instances of cancer will increment from about 14 million of every 2012 to 22 million out of 2030, with most cases in LMICs situated in Africa, Asia and Latin America [31]. The anticipated increment in cancer frequency is anticipated to be most noteworthy in LMICs in Asia. In these countries, over $60 \%$ of the complete healthcare consumption originates from private assets, of which over $80 \%$ is immediate OOP payments, with disastrous outcomes for most families in these countries [25]. In India alone, upwards of 63 million individuals are constrained into poverty consistently, inferable from calamitous health costs, most of which are OOP payments for medicines [32]. Hereditary inclination, expanding future, urbanization, automation, insufficient health administrations and quick financial improvement powering stationary quality and changing dietary examples are adding to rising chronic disease trouble in the South Asian area [33]. Rijal et.al, 2018 detailed that Afghanistan, Bangladesh, Bhutan, Maldives, Nepal, India, Pakistan and Sri Lanka, which are for the most part LMICs with provincial GDP per capita 1640 USD and home to a fourth of world populace [34]. As indicated by Giri et.al, 2018 bosom cancer was the most common cancer and fourth driving cause of cancer-related mortality among ladies in Asia [35]. Siegel et.al, 2019 states death rates in the least fortunate regions were 2-overlay higher than most prosperous provinces for cervical cancer and $40 \%$ higher for male lung and liver cancers during 2012-2016 [36]. 33\% of the world cervical cancer weight is suffered in India, Bangladesh, Nepal and Sri Lanka. High-hazard HPV types were found in $97 \%$ of cervical cancers, and HPV-16 and 18 were found in $80 \%$ of cancers in India [37]. Stomach cancer $(9 \cdot 0 \%)$, bosom cancer $(8 \cdot 2 \%)$, lung cancer $(7 \cdot 5 \%)$, lip and oral pit cancer $(7 \cdot 2 \%)$, pharynx cancer other than nasopharynx (6.8\%), colon and rectum cancer $(5 \cdot 8 \%)$, leukemia $(5 \cdot 2 \%)$, and cervical cancer $(5 \cdot 2 \%)$ are the main sorts of cancer in India in 2016 [38]. India has been outstanding in the global oncology network as the nation where cancer medication 
costs are less expensive contrasted with different countries. For example, the 4 -week by week cost of trastuzumab was $\$ 2761$ in India versus $\$ 6849$ in the US [39]. It was to be sure encouraging to see that India paid $\$ 19000$ for a 4 -week course of bevacizumab (in view of acquiring power equality) while Australia paid just \$543 [40]. In the US, people determined to have cancer are 2.7 occasions bound to bow out of all financial obligations, than people without cancer [41]. Saqib et.al, 2018 expressed that patients in LMICs think that it's hard to manage the cost of non-biologics and their treatment with new restorative operators like biologic is practically outlandish. In this manner, the administration of cancer is genuinely influenced by the accessibility and affordability of anticancer operators [42]. Because of absence of data on relative medication costs and quality, it is hard for doctors to recommend the most efficient treatment. Absence of data on quality, non-accessibility and irreconcilable situations are additionally in charge of doctors not recommending the most affordable drug. The distinction in cost between the different brands of a similar medication shifts from 2-crease to more than 100 -overlay in India [43]. Bhutan (13\%), Maldives (5\%) and Timor-Leste (5\%) - are little countries with testing topographies that come up short on the limit with regards to nearby pharmaceutical generation. They may likewise use elective systems, for example, sending patients with cancer for treatment abroad [26]. Numerous instances of high medication costs exist and are often examined in the media. One regularly referenced model is imatinib (brand name Gleevec®), a medication for chronic myeloid leukemia, which significantly increased in cost after the US FDA allowed for another sign. Novartis raised its cost from $\$ 31,930$ in 2005 to $\$ 118,000$ every year in 2015 in spite of a gigantic increment in the volumes sold [44]. The nineteenth modification of the WHO EML in 2015 included 16 essential cancer drugs, including three staggering expense medicines, imatinib, rituximab and trastuzumab, and in this manner improving fair access to imaginative treatments for cancer that are generally inaccessible in low-asset settings [45]. India is one of the top global funders of R\&D into disregarded diseases, as indicated by Thomas et.al, 2019. About 12\% of medication, indicative, and immunization candidates for ignored diseases in the R\&D pipeline are from India [46]. Most South Asian countries have very much spread out administrative pathways for biosimilar endorsement. While no biosimilar insulin is affirmed in USA as of date August 2015, the European Medicines Agency and Japanese medication administrative experts have offered endorsement to just a single insulin-a biosimilar insulin glargine delivered by Eli Lilly [47]. One of the most noteworthy wellbeing worries with biosimilars is the potential danger of safe based unfavorable responses. Because of their atomic size, biologics can legitimately actuate against medication antibodies which may have critical ramifications for both wellbeing and viability [48]. As makers of biosimilar items don't approach the phone line and strategy of reference item, the assembling procedure may change marginally, yet this may have huge effect on the natural capacity of the item, including immunogenicity, possibly influencing the security and viability profile [49]. Likewise, the costs of medication dispersion in India are 2 to multiple times more prominent than in the United States or the European Union, in spite of immeasurably lower work costs. Their staffs are not required to indicate aptitudes in pharmaceutical warehousing and the executives, regularly with tragic results [50]. The month to month medication costs were the most astounding in the U.S and lowest in India. Be that as it may, regardless of having the lowest medication costs, drugs were the least reasonable (affordability evaluated as medication costs separated by GDP per capita or normal compensation) in India [39,40]. Those drugs that guarantee fix ought to be given the main need. The administrations and strategy producers in LMICs ought to organize access to profoundly successful biotech drugs used in therapeutic setting and cutoff spending on costly yet insufficient or insignificantly viable drugs used in palliative setting. Bury joint efforts between the BRICS countries like Brazil, China and India need to establish the tone and make more motivating forces to build nearby generation of drugs with LMICs [51]. There are different mediations or changes in approaches exhorted that can help in lowering the cost of biotech drugs like breaking the syndication in medication makers, changing the administrative rules by government offices for those organizations which production less expensive drugs and making the new medication endorsements quicker, expanding the cost adequacy proportion of drugs, accomplishing a harmony between doctor self-governance in recommending biotech drugs and costs caused by patients, empowering non-benefit nonexclusive organizations which assembling biotech drugs by giving them charge motivating forces and different measures, esteem based repayment by restorative insurance agencies.

\section{ACKNOWLEDGEMENT}

I'm thankful to Gautam Kumar Saha, Apollo Hospitals Educational and Research Foundation, New Delhi, India for his precious time to review my letter to the editor and for his thoughtful suggestions. I'm also grateful to seminar library of Faculty of Pharmacy, University of Dhaka and BANSDOC Library, Bangladesh for providing me books, journal and newsletters.

\section{ABBREVIATIONS}

Partnership for Influenza Vaccine Introduction (PIVI); National Immunization Technical Advisory Groups (NITAGs); Out-ofpocket (OOP); Low-and Middle-Income Countries (LMICs); Randomized Control Trial (RCT); Human Papillomavirus (HPV); Gross Domestic Product (GDP); Essential Medicine List (EML); Research and Development (R\&D); Brazil, Russia, India, China and South Africa (BRICS countries); Non-communicable diseases (NCDs); Cardiovascular Diseases (CVDs)

Financial Disclosure or Funding: N/A

Conflict of Interest: The author declares that he has no competing interests.

Informed Consent: N/A

Author contributions: N/A 


\section{REFERENCES}

1. Beck, E. J., Mandalia, S., DongmoNguimfack, B., Pinheiro, E., 't Hoen, E., Boulet, P., ... \& Ghys, P. (2019). Does the political will exist to bring quality-assured and affordable drugs to low-and middle-income countries?. Global health action, 12(1), 1586317.

2. Philippidis, A. (2019). Top 15 Best-Selling Drugs of 2018: Sales for most treatments grow year-over-year despite concerns over rising prices. Genetic Engineering \& Biotechnology News, 39(4), 16-17.

3. IQVA. The Global Use of Medicine in 2019 and Outlook to 2023: Forecasts and Areas to Watch. Institute Report, January 29, 2019.

4. Stevens, H., \& Huys, I. (2017). Innovative approaches to increase access to medicines in developing countries. Frontiers in medicine, 4, 218.

5. Faruqui, N., Martiniuk, A., Sharma, A., Sharma, C., Rathore, B., Arora, R. S., \& Joshi, R. (2019). Evaluating access to essential medicines for treating childhood cancers: a medicines availability, price and affordability study in New Delhi, India. BMJ global health, 4(2), e001379.

6. Lexchin, J. (2013). Canada and access to medicines in developing countries: intellectual property rights first. Globalization and health, 9(1), 42.

7. Moon, S. (2017). Powerful ideas for global access to medicines. New England Journal of Medicine, 376(6), 505-507.

8. Prinja, S., Bahuguna, P., Tripathy, J. P., \& Kumar, R. (2015). Availability of medicines in public sector health facilities of two North Indian States. BMC Pharmacology and Toxicology, 16(1), 43.

9. Oberoi, S. S., \& Oberoi, A. (2014). Pharmacoeconomics guidelines: The need of hour for India. International journal of pharmaceutical investigation, 4(3), 109.

10. Ewen, M., Zweekhorst, M., Regeer, B., \& Laing, R. (2017). Baseline assessment of WHO's target for both availability and affordability of essential medicines to treat non-communicable diseases. PloS one, 12(2), e0171284..

11. Khuluza, F., \& Haefele-Abah, C. (2019). The availability, prices and affordability of essential medicines in Malawi: A crosssectional study. PloS one, 14(2), e0212125.

12. Ahmadiani, S., \& Nikfar, S. (2016). Challenges of access to medicine and the responsibility of pharmaceutical companies: a legal perspective. DARU Journal of Pharmaceutical Sciences, 24(1), 13.

13. FM't Hoen, E., Kujinga, T., \& Boulet, P. (2018). Patent challenges in the procurement and supply of generic new essential medicines and lessons from HIV in the southern African development community (SADC) region. Journal of pharmaceutical policy and practice, 11(1), 31

14. Scavone, C., Sportiello, L., Sullo, M. G., Ferrajolo, C., Ruggiero, R., Sessa, M., ... \& Rafaniello, C. (2017). Safety profile of anticancer and immune-modulating biotech drugs used in a real world setting in Campania region (Italy): bio-cam observational study. Frontiers in pharmacology, 8, 607.

15. Goldman, D. P., Joyce, G. F., Lawless, G., Crown, W. H., \& Willey, V. (2006). Benefit design and specialty drug use. Health Affairs, 25(5), 1319-1331.

16. VOGENBERG, F. R., \& YOUNG, C. (2004). Biotech injectable drugs: Clinical applications and financial effects. Biotechnology healthcare, 1(3), 31.

17. Jayasundara, K., Hollis, A., Krahn, M., Mamdani, M., Hoch, J. S., \& Grootendorst, P. (2019). Estimating the clinical cost of drug development for orphan versus non-orphan drugs. Orphanet journal of rare diseases, 14(1), 12.

18. EDELMAN, B. (2004). Explaining the cost of biotech therapies. Biotechnology healthcare, 1(2), 37.

19. Kunnumakkara, A. B., Bordoloi, D., Sailo, B. L., Roy, N. K., Thakur, K. K., Banik, K., .. \& Aggarwal, B. B. (2019). Cancer drug development: The missing links. Experimental Biology and Medicine, 1535370219839163.

20. Scavone, C., di Mauro, G., Mascolo, A., Berrino, L., Rossi, F., \& Capuano, A. (2019). The new paradigms in clinical research: from Early Access Programs to the novel therapeutic approaches for unmet medical needs. Frontiers in pharmacology, 10.

21. Gouglas, D., Le, T. T., Henderson, K., Kaloudis, A., Danielsen, T., Hammersland, N. C., ... \& Røttingen, J. A. (2018). Estimating the cost of vaccine development against epidemic infectious diseases: a cost minimisation study. The Lancet Global Health, 6(12), e1386-e1396.

22. Simon, R. (2017). Critical review of umbrella, basket, and platform designs for oncology clinical trials. Clinical Pharmacology \& Therapeutics, 102(6), 934-941.

23. Tay-Teo, K., Ilbawi, A., \& Hill, S. R. (2019). Comparison of sales income and research and development costs for fda-approved cancer drugs sold by originator drug companies. JAMA network open, 2(1), e186875-e186875.

24. Kaufman, H. L., Atkins, M. B., Subedi, P., Wu, J., Chambers, J., Mattingly, T. J., ... \& Danielson, D. (2019). The promise of Immuno-oncology: implications for defining the value of cancer treatment. Journal for immunotherapy of cancer, 7(1), 129.

25. Salmasi, S., Lee, K. S., Ming, L. C., Neoh, C. F., Elrggal, M. E., Khan, T. M., \& Hadi, M. A. (2017). Pricing appraisal of anticancer drugs in the South East Asian, Western Pacific and East Mediterranean region. BMC cancer, 17(1), 903.

26. Chivukula, M. V., \& Tisocki, K. (2018). Essential cancer medicines in the national lists of countries of the WHO South-East Asia Region: a descriptive assessment. WHO South-East Asia journal of public health, 7(2), 90.

27. Krzyszczyk, P., Acevedo, A., Davidoff, E. J., Timmins, L. M., Marrero-Berrios, I., Patel, M., ... \& O’Neill, K. M. (2018). The growing role of precision and personalized medicine for cancer treatment. Technology, 6(03n04), 79-100.

28. Moreno, S. G., \& Epstein, D. (2019). The price of innovation-the role of drug pricing in financing pharmaceutical innovation. A conceptual framework. Journal of market access \& health policy, 7(1), 1583536. 
29. Ba-Nguz, A., Shah, A., Bresee, J. S., Lafond, K. E., Cavallaro, K., Shefer, A., ... \& Seward, J. F. (2019). Supporting national immunization technical advisory groups (NITAGs) in resource-constrained settings. New strategies and lessons learned from the Task Force for Global Health's Partnership for influenza vaccine introduction. Vaccine, 37(28), 3646-3653.

30. Owoeye, O. (2018). Biologics and Public Health: Prospects and Challenges. Journal of law and medicine, 26(1), $170-187$.

31. Wilking, N., Lopes, G., Meier, K., Simoens, S., van Harten, W., \& Vulto, A. (2017). Can we continue to afford access to cancer treatment. European Oncology and Haematology, 13.

32. Barrios, C. H., Reinert, T., \& Werutsky, G. (2019). Access to high-cost drugs for advanced breast cancer in Latin America, particularly trastuzumab. ecancermedicalscience, 13.

33. Paudel, S., Owen, A. J., Owusu-Addo, E., \& Smith, B. J. (2019). Physical activity participation and the risk of chronic diseases among South Asian adults: a systematic review and meta-analysis. Scientific reports, 9(1), 9771.

34. Rijal, A., Adhikari, T. B., Khan, J. A., \& Berg-Beckhoff, G. (2018). The economic impact of non-communicable diseases among households in South Asia and their coping strategy: A systematic review. PloS one, 13(11), e0205745.

35. Giri, M., Giri, M., Thapa, R. J., Upreti, B., \& Pariyar, B. (2018). Breast Cancer in Nepal: Current status and future directions. Biomedical reports, 8(4), 325-329.

36. Siegel, R. L., Miller, K. D., \& Jemal, A. (2019). Cancer statistics, 2019. CA: a cancer journal for clinicians, 69(1), 7-34.

37. Sankaranarayanan, R., Bhatla, N., Gravitt, P. E., Basu, P., Esmy, P. O., Ashrafunnessa, K. S., ... \& Nene, B. M. (2008). Human papillomavirus infection and cervical cancer prevention in India, Bangladesh, Sri Lanka and Nepal. Vaccine, 26, M43-M52.

38. Dhillon, P. K., Mathur, P., Nandakumar, A., Fitzmaurice, C., Kumar, G. A., Mehrotra, R., ... \& Thakur, J. S. (2018). The burden of cancers and their variations across the states of India: the Global Burden of Disease Study 1990-2016. The Lancet Oncology, 19(10), 1289-1306.

39. Gyawali, B. (2017). Cancer drugs in LMICs: cheap but unaffordable. Oncotarget, 8(52), 89425.

40. Goldstein, D. A., Clark, J., Tu, Y., Zhang, J., Fang, F., Goldstein, R., ... \& Rosenbaum, E. (2017). A global comparison of the cost of patented cancer drugs in relation to global differences in wealth. Oncotarget, 8(42), 71548.

41. Ramsey, S., Blough, D., Kirchhoff, A., Kreizenbeck, K., Fedorenko, C., Snell, K., ... \& Overstreet, K. (2013). Washington State cancer patients found to be at greater risk for bankruptcy than people without a cancer diagnosis. Health affairs, 32(6), 11431152.

42. Saqib, A., Iftikhar, S., \& Sarwar, M. R. (2018). Availability and affordability of biologic versus non-biologic anticancer medicines: a cross-sectional study in Punjab, Pakistan. BMJ open, 8(6), e019015.

43. Kolasani, B. P., Malathi, D. C., \& Ponnaluri, R. R. (2016). Variation of cost among anti-cancer drugs available in Indian market. Journal of clinical and diagnostic research: JCDR, 10(11), FC17.

44. van der Gronde, T., Uyl-de Groot, C. A., \& Pieters, T. (2017). Addressing the challenge of high-priced prescription drugs in the era of precision medicine: A systematic review of drug life cycles, therapeutic drug markets and regulatory frameworks. PloS one, 12(8), e0182613.

45. Eniu, A., Torode, J., Magrini, N., \& Bricalli, G. (2015). Union for International Cancer Control EML Steering Committee Members. Back to the 'essence'of medical treatment in oncology: the.

46. Thomas, Z., Saha, G. K., Gopakumar, K. M., \& Ganguly, N. K. (2019). Can India lead the way in neglected diseases innovation?. bmj, 364, k5396.

47. Kalra, S., Khan, A. A., Raza, S. A., Somasundaram, N., Shrestha, D., Latif, Z. A., ... \& Mahtab, H. (2016). Biosimilar insulins: informed choice for South Asia. Indian journal of endocrinology and metabolism, 20(1), 5.

48. Mohiuddin,A.K. (2019). Safety Issues of Biosimilar Products. J Cancer Res Therap Oncol 7: 1-4.

49. Kaduskar, P. U. (2016). Biosimilar insulins: an unavoidable option in South-East Asia. Indian journal of endocrinology and metabolism, 20(4), 574.

50. Buckley, G. J., \& Gostin, L. O. (Eds.). (2013). Countering the problem of falsified and substandard drugs. National Academies Press.

51. Ezziane, Z. (2014). Essential drugs production in Brazil, Russia, India, China and South Africa (BRICS): opportunities and challenges. International journal of health policy and management, 3(7), 365. 